\title{
Superparamagnetic maghemite loaded poly ( $\varepsilon$ - caprolactone) nanocapsules : characterization and synthesis optimization
}

\author{
Marcela F. Silva* ${ }^{1}$, Mariani A. Ciciliatti ${ }^{1}$, Ana Adelina W. Hechenleitner ${ }^{1}$, \\ Rebeca Peñalva ${ }^{2}$, Maite Agüeros ${ }^{2}$, Juan Manuel Irache ${ }^{2}$, Adilson J. A. de Oliveira ${ }^{3}$, \\ Ammad A. Farooqi ${ }^{4}$, Edgardo A. G. Pineda ${ }^{1}$
}

\author{
${ }^{1}$ Departamento de Química, Universidade Estadual de Maringá, Av. Colombo 5790, 87020-900, Maringá-PR, Brasil \\ e-mail: celafs@gmail.com \\ ${ }^{2}$ Departamento de Farmacia y Tecnología Farmacéutica, Universidad de Navarra, 31080, Pamplona, Spain \\ ${ }^{3}$ Departamento de Física, Universidade Federal de São Carlos, Rod. Washington Luís, km 235, 13565-905, São Carlos, \\ SP, Brazil \\ ${ }^{4}$ Laboratory for Translational Oncology and Personalized Medicine, RLMC, 35 Km Ferozepur Road, Lahore, Pakistan
}

\begin{abstract}
Iron oxide nanoparticles (ION) have been studied for essential applications, like detection of biological constituents (virus, bacterials, cell, nucleic acids, protein, enzyme, etc.), magnetic bioseparation and clinic therapy and diagnosis (such as MRI magnetic fluid and hyperthermia). In this work, $\gamma-\mathrm{Fe}_{2} \mathrm{O}_{3}$ has been synthetized by a adapted sol-gel method and entraped in poly $\varepsilon$-caprolactone (PCL) nanocapsules. The superparamagnetic nanocapsules have been formulated by double emulsion evaporation method. Some variables affecting the polydispersity index, zeta potential surface and size of nanocapsules were studied aiming optimize the formulation process of maghemite-loaded PCL nanocapsules. The following parameters were selected: sonication time, PCL concentration in organic phase, PVA concentration in external aqueous phase and maghemite/PCL weight ratio. Under these experimental conditions, the resulting nanocapsules displayed a mean size of about $346 \mathrm{~nm}$ and a maghemite content of about $7.5 \mu \mathrm{g} / \mathrm{mg}$ of nanocapsules and superparamagnetic behaviour at room temperature.
\end{abstract}

Keywords: maghemite, nanocapsules, optimization, poly ( $\varepsilon$ - caprolactone), superparamagnetism.

\section{INTRODUCTION}

There have been great commitments for the studies of synthesis of organic/inorganic nanocomposites in order to obtain novel hybrid characteristics derived from the components. Due to the small size of nanoparticle, they offer different properties. For example, nanomagnetic particles based on iron oxide composites are gaining great importance in the area of biomedical sciences, like for hyperthermia, immunoassay, targeted drug delivery, DNA purification and identification, cell isolation and protein and enzyme immobilization [1- 4]. Among the main iron oxides, maghemite $\left(\gamma-\mathrm{Fe}_{2} \mathrm{O}_{3}\right)$ and magnetite $\left(\mathrm{Fe}_{3} \mathrm{O}_{4}\right)$ are the most popular and promising candidates for biological applications since their biocompatibility have already been proven [5].

In general, iron oxide nanoparticles (ION) display some inherent drawbacks that difficult their use for biomedical applications, including their tendency to aggregate and the limited targeting properties [6]. In order to solve these inconveniences, one possible solution may be their coating with biodegradable and biocompatible polymers. This approach permits to yield nano/microparticulates which are more easily handled than ION and that offer additional properties such as (i) the possibility of co-encapsulate a drug (ii) controlled release profiles and/or (iii) targeting abilities by simple modification of the surface of the resulting particulates. Among others the following materials have been proposed: poly(lactide-co-glycolide) (PLGA), polyethylene glycol (PEG), chitosan, poly(vinyl alcohol) (PVA) and poly \&-caprolactone (PCL) [7 - 11].

Among these polymers, poly $\varepsilon$-caprolactone has a molecular structure of five non-polar methylene groups and one comparatively polar ester group. The biodegradability of this polymer is induce by the presence of hydrolysis-unstable aliphatic ester linkage. It is degraded to a low molecular weight nontoxic by-product in line with drug release by biodegradation thereof [12].

Nevertheless, the hydrophobic character of this polymer hampers the entrapment and encapsulation of iron oxide nanoparticles. Actually, the great challenge is how to entrap, in a sufficient amount, ION into PCL par- 
ticles in order to achieve a system capable to be applied for hyperthermia applications among others. In the last years, one common solution has been the use of oleic acid in order to render more hydrophobic the surface of ION and thus more compatible with the nature of polymers [13 - 15]. Though oleic acid has been accepted as an unsaturated fatty acid with lots of advantages to human body, presently, some researches has been pondering possible disadvantage that oleic acid may cause to the human health [16]. The results report that exposure of low amount of oleic acid prejudices the barrier function of the intestinal epithelium, like actions that prevent absorption of toxic substances present in food [17 - 19$]$.

Due to this, the object of this work was to develop a method to entrap iron oxide nanoparticles in PCL nanocapsules in the absence of oleic acid. Moreover we have concentrated our work on the optimization of nanocapsules formulation. Particularly, the effects of surfactant, sonication time, iron oxide amount and polymer have been studied with respect to their action on the physico-chemical properties of the resulting iron oxide loaded PCL nanocapsules.

\section{EXPERIMENTAL}

\subsection{Materials}

Poly(vinyl alcohol) (PVA; MW 146,000-180,000 88-89\% hydrolyzed) (Aldrich,USA), Ferric nitrate $\left(\mathrm{Fe}\left(\mathrm{NO}_{3}\right)_{3} .9 \mathrm{H}_{2} \mathrm{O}\right)$ (Vetec, Brazil), Poly $\varepsilon$-caprolactone (PCL, MW 65,000, Aldrich, USA), Pluronic F-68 (Sigma-Aldrich, USA), sodium citrate tribasic dehydrate (ACS 99\%- Sigma Aldrich, USA), dichlorometane (99\%, Merck, Germany), sucrose (Fragon, Spain).

\subsection{Synthesis of maghemite nanoparticles (Mag)}

The maghemite nanoparticles (Mag) of average size of $15 \mathrm{~nm}$ were obtained by a adapted sol-gel method. [20] Aqueous PVA solution $(10 \% \mathrm{w} / \mathrm{v})$ and saturated ferric nitrate solution were mixed at metallic ion/monomer unit ratio of 1:18. The mixture was maintained at room temperature under stirring for $2 \mathrm{~h}$ and after heated under magnetic stirring until total water evaporation. The temperature was maintained at about $150^{\circ} \mathrm{C}$ for thermal degradation of the PVA. The nanoparticles were obtained after calcination of the material at $400^{\circ} \mathrm{C}$ under air atmosphere for $4 \mathrm{~h}$.

\subsection{Formulation of maghemite loaded-PCL nanocapsules (MagPCL-NC)}

Mag-loaded in PCL nanocapsules were obtained by a multiple emulsion $\left(\mathrm{W}_{1} / \mathrm{O} / \mathrm{W}_{2}\right)$ method adapted to this particular case [21]. Briefly, Mag was dispersed in $0.5 \mathrm{ml}$ of an inner water phase containing $1 \% \mathrm{w} / \mathrm{v}$ sodium citrate by ultrasonication (Microson ultrasonic cell disruptor XL, Misonix, USA) for 1 min. This dispersion was, then, emulsified in $1 \mathrm{~mL}$ of an organic phase of PCL dissolved in dichloromethane and $0.5 \mathrm{~mL}$ of $6 \%$ w/v Pluronic F-68. This $\mathrm{W}_{1} / \mathrm{O}$ emulsion previously formed was then finally dispersed in $5 \mathrm{~mL}$ of a PVA aqueous phase of PVA under sonication. The time of sonication at a frequency of $20 \mathrm{kHz}$ for the second emulsification step were varied in 1, 3 and 5 min. [PCL] in organic phase was varied in 100, 200 and 400 mg.mL ${ }^{-1}$. The concentration of PVA in aqueous outer aqueous phase was varied in $0.5,1$ and $2 \%$ and the initial ratio of maghemite/PCL was varied in $0.02,0.05$ and $0.1 \mathrm{mg} / \mathrm{mg}$. The resulting multiple emulsions were stirred with a blade stirrer at room temperature to evaporate the dichloromethame. The resulting nanocapsules were, firstly, centrifuged at 1,000 rpm for $20 \mathrm{~min}$ in order to eliminate unloaded Mag and, secondly, were washed two times with distilled water by consecutive centrifugation (Biofuge Stratus, Heraeus Instruments, Germany) at 17,000 r.p.m. for $10 \mathrm{~min}$ at $4^{\circ} \mathrm{C}$. The pellet was dispersed in $3 \mathrm{ml}$ aqueous solution containing 5\% sucrose as cryoprotector and the formulations were freeze-dried in a Genesis 12EL apparatus (Virtis, USA). Empty PCL nanocapsules were formulated as described above without using Mag and used as control.

\subsection{Characterization}

The surface zeta potential and size of Mag nanoparticles and MagPCL-NC were determined by electrophoretic laser Doppler anemometry and photon correlation spectroscopy, respectively, by a Zetamaster analyzer system (Malvern Instruments, UK). Samples were dispersed with deionized water at $25^{\circ} \mathrm{C}$ for size measurements, and measured with a scattering angle of $90^{\circ}$ and for zeta potential measurements; samples were dispersed in aqueous solution of $\mathrm{KCl} 0.3 \mathrm{mM}$ at $\mathrm{pH} 3-10$. The mean hydrodynamic diameter was determined by 
fitting the autocorrelation function with the the cumulant method, which also gives the polydispersity index (PDI) (equation 2), which is defined as: [22]

$$
P D I=\frac{R_{i-1} R_{i+1}}{\left(R_{i}\right)^{2}}
$$

where $\mathrm{Ri}$ is the ith moment of the particle size distribution.

For mean diameter determinations the error bar shows the width of the distribution and for the PDI measurements the error bar reports the standard deviation obtained from three measurements.

The morphology and shape of nanocapsules were studied by electron microscopy. Mag-loaded PCL nanocapsules were negatively stained with phosphotungstic acid before observation in the TEM apparatus (EM10, Zeiss, USA).For the observation of nanocapsules by using a Field Emission Scanning Electron Microscope (Carl Zeiss Ultra Plus, Germany), the samples were mounted on carbon coated TEM copper grids (carbon films on $3 \mathrm{~mm} 400$ mesh grids, Agar Scientific) and placed in a desiccator in order to evaporate water. Finally, the grids were adhered with a double-sided adhesive tape onto metal stubs for SEM visualization.

\subsection{Amount of Mag-loaded in nanocapsules}

For determination of the entrapment of maghemite nanoparticles encapsulated in the PCL nanocapsules, 20 $\mathrm{mg}$ of MagPCL-NC were digested in $20 \mathrm{~mL} \mathrm{HCl} 18.5 \%$ during $2 \mathrm{~h}$ at $70^{\circ} \mathrm{C}$. The obtained solutions were diluted in water and the iron concentration in samples was measured at $248.4 \mathrm{~nm}$ in an atomic absorption spectrophotometry (AAS) using acetylene-air flame in a Varian AA10 plus apparatus (Varian, Australia). The assay was linear between 0 and $8 \mu \mathrm{g} / \mathrm{ml}$ with a correlation coefficient of 1.0

The amount of maghemite entraped in optimized MagPCL-NC was determined from the amount of iron measured by AAS. Maghemite entrapment efficiency $(\%)$ and maghemite content $(\% \mathrm{w} / \mathrm{w})$ were calculated by equations 2 and 3, respectively:

Maghemite entrapment efficiency (\%):

$$
=\frac{\text { Mass of maghemite in MagPCL-NC }}{\text { Mass of maghemite used in formulation }}
$$

Maghemite content (\% w/w):

$$
=\frac{\text { Mass of maghemite in MagPCL-NC }}{\text { Mass of MagPCL-NC }}
$$

\subsection{Magnetic Characterization}

The magnetic characterization was performed using the MPMS3 - SQUID magnetometer by Quantum Design trough the vibrating sample magnetometer (VSM) technique. The magnetization measurements as a function of applied magnetic field were performed up to $300 \mathrm{~K}$. The magnetization measurements as a function of temperature were performed using the ZFC (zero field cooling) and FC (field cooling) protocol.

\section{RESULTS AND DISCUSSION}

\subsection{Optimization of Maghemite-loaded PCL nanocapsules}

Several process parameters were assessed in order to achieve optimal preparation conditions, including: time of sonication to prepare the second emulsion, PCL content in the formulation, the initial Mag/PCL weight ratio and the PVA concentration in the outer aqueous phase. The influence of these parameters, such as organic-to-water phase ratio,emulsifier concentration, polymer concentration, stirring rate and polymer molecular weight have already been investigated $[23,24]$.

From a general point of view, all the formulation prepared within this optimization study did not significantly affect the zeta potential of the resulting MagPCL-NC, measured at $\mathrm{pH} 7$, which remains in the range of -1 and $-8 \mathrm{mV}$. These values for MagPCL-NC zeta potential are in agreement with previous results presented 
for PCL nanoparticles. The negative values reflect the presence of carboxylic groups at the polymer extremities, since PCL is a polyester $[25,26]$.

\subsubsection{Sonication time during the emulsification step}

In order to obtain emulsified systems, the addition of energy is a fundamental step. In this work, the emulsion process was carried out in two stages: at first, the internal aqueous phase containing maghemite was emulsified with a PCL organic solution. Then, this emulsion was afresh emulsified with an outer PVA aqueous solution phase.

The ultrasonication is characterized by a complex dynamics of collisions, coalescence, and breakage of droplets, which reaches a dynamic equilibrium only after a sufficient time. Afterwards, the droplet size distribution stabilizes, being usually characterized by a low polydispersity in the final emulsion [27].

Erro! Fonte de referência não encontrada. summarizes the influence of the sonication time during the second emulsification stage on the physico-chemical properties of the resulting nanocapsules. From this results, it was clear that a sonication time of 3 or 5 minutes allowed us to obtain nanocapsules with a small size (around $300 \mathrm{~nm}$ ) and a considered satisfactory polydispersity (PDI) (about 0.3) [28]. When the sonication time was lower than 3 minutes, the resulting nanocapsules displayed a mean size higher than $300 \mathrm{~nm}$ and a moderate heterogenicity (PDI about 0.37 ). This behaviour is in agreement with previous data presented in the literature for polymeric nanocapsules $[29,30]$.

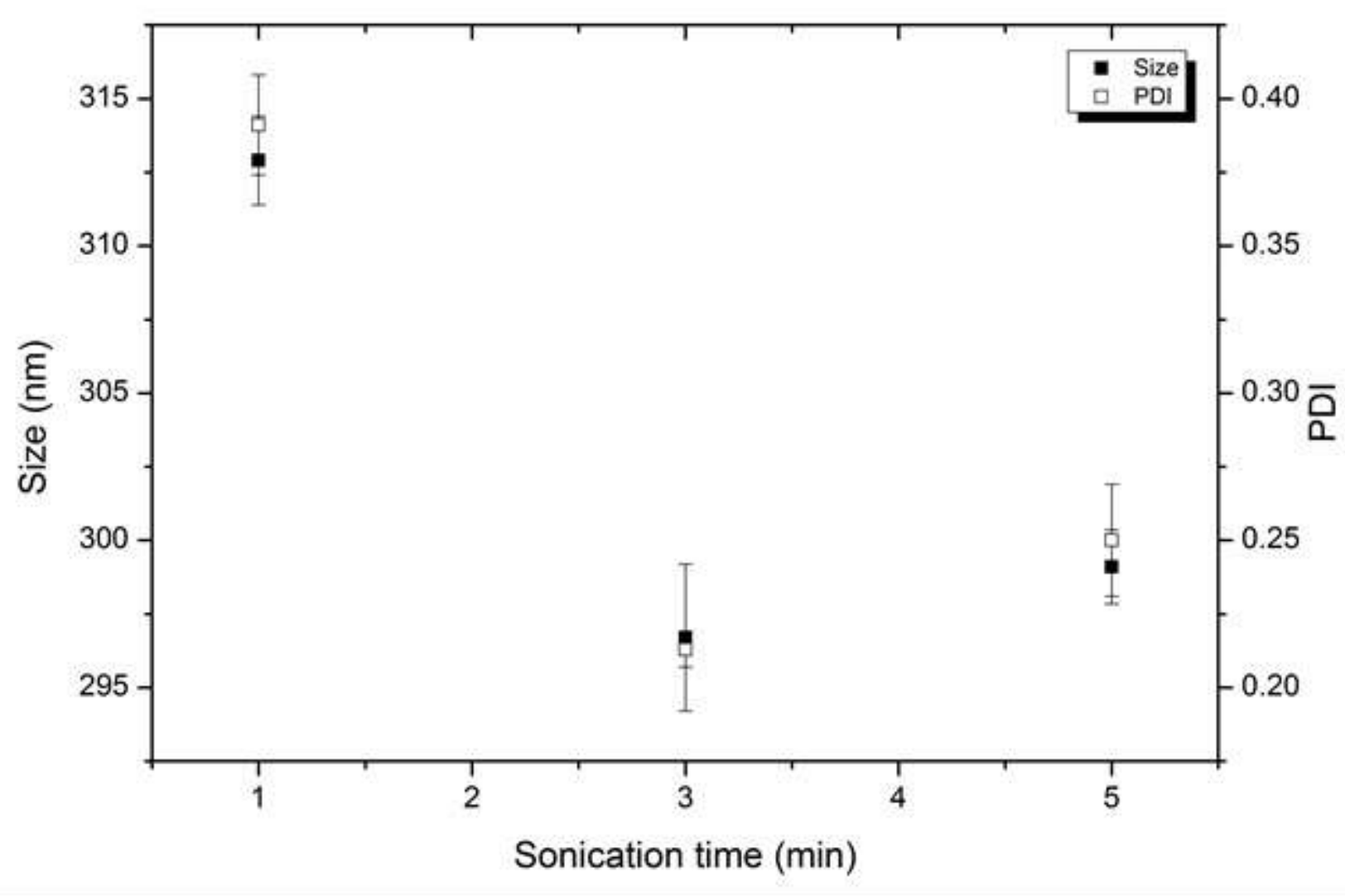

Figure 1: Influence of the time of emulsification by sonication on the average hydrodynamic size and PDI of the resulting MagPCL-NC. Data expressed as mean \pm SD $(n=3)$. Experimental conditions: PCL: $100 \mathrm{mg}$; initial Mag added: 5 mg; PVA concentration: $1 \% \mathrm{w} / \mathrm{v}$.

\subsubsection{PVA concentration in the outer aqueous phase}

The concentration of emulsifier is probably the variable that strongly influences the theoretical final particle diameter. In order to show the effect of PVA on the particle diameter and diameter distribution of system, the 
concentration was varied between 0.5 and $2 \%$.

Figure 1 shows the influence of the PVA content in the outer aqueous phase on the properties of the resulting MagPCL-NC. At the lowest PVA concentration $(0.5 \% \mathrm{w} / \mathrm{v})$ the size of the resulting nanocapsules was found to be around $350 \mathrm{~nm}$ with a PDI of 0.3 . On the contrary, by increasing the PVA concentration till $1 \% \mathrm{w} / \mathrm{v}$, both the size and polydispersity of the resulting nanoparticles decreased (around $195 \mathrm{~nm}$ with a PDI about than 0.2 ). Nevertheless, the preparation of nanocapsules with concentrations of PVA higher than $1 \%$, induced an increasing of the resulting size and polydispersity. This finding would be also an evidence that with the increasing in PVA concentration, the viscosity of the outer aqueous phase increased in the same way, which resulted in size increase due to decrease in the net shear stress $[31,32]$

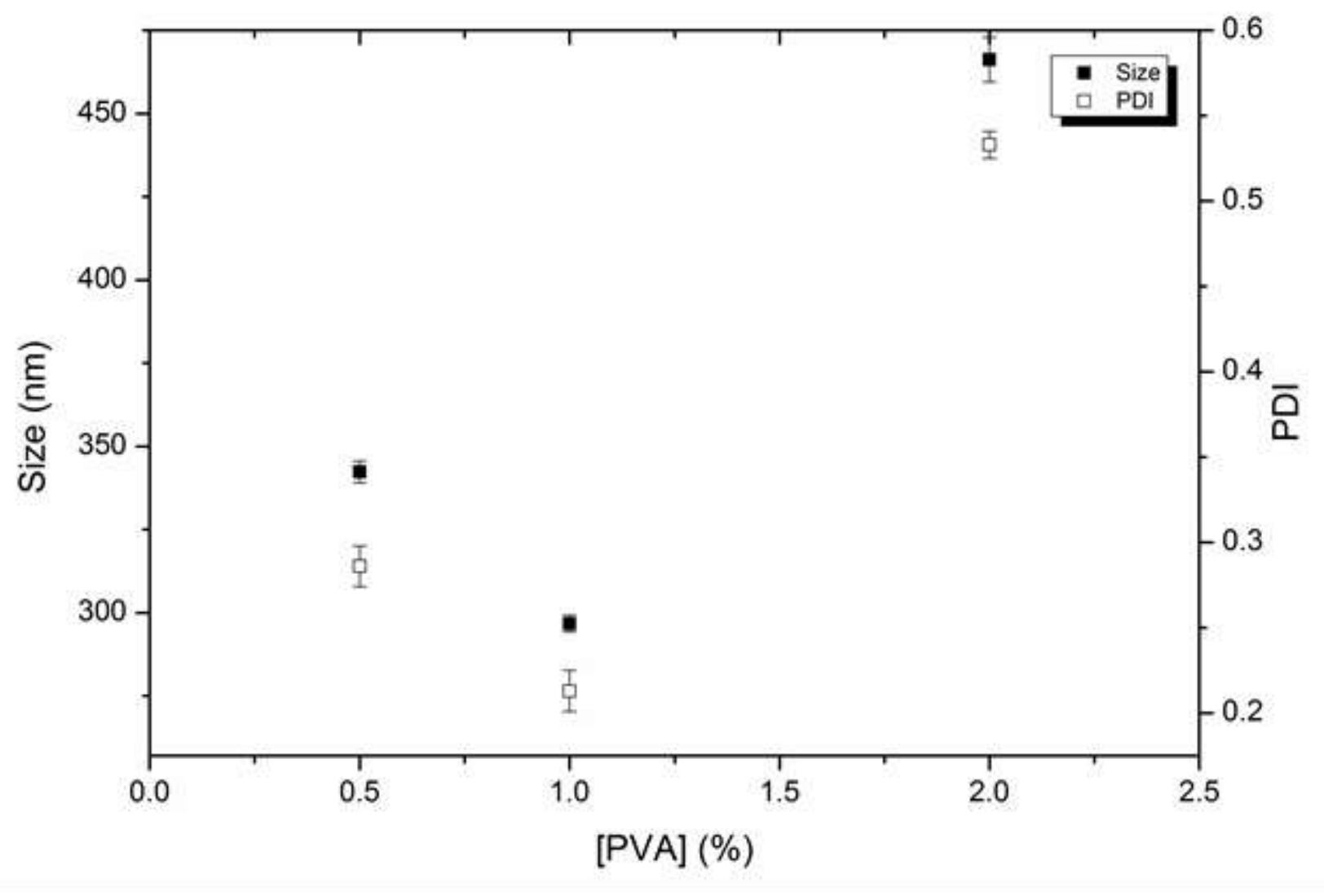

Figure 1: Influence of the PVA concentration on the average hydrodynamic size and PDI of the resulting MagPCL-NC. Data expressed as mean \pm SD $(n=3)$. Experimental conditions: PCL: $100 \mathrm{mg}$; initial Mag added: $5 \mathrm{mg}$; Time of sonication: $3 \mathrm{~min}$.

\subsubsection{PCL concentration}

PCL amount in the oil phase was varied between 50 and $200 \mathrm{mg} \cdot \mathrm{mL}^{-1}$, and the influence of this parameter on the mean diameter and diameter distribution of the resulting nanocapsules was studied. Erro! Fonte de referência não encontrada. shows the evolution of the size and polidispersity of the MAgPCL-NC as a function of the PCL amount used to prepare these carriers. In this case the mean diameter of nanocapsules slightly increases (nearly 300 to $360 \mathrm{~nm}$ ) by increasing the PCL concentration from 50 to $200 \mathrm{mg} \cdot \mathrm{mL}^{-1}$. This fact would be consequence of an increase in both the viscosity and the surface tension of the organic phase in which PCL was dissolved and, hence reducing the net shear stress and promoting formation of droplets with a large size [32]. Furthermore, PVA was probably insufficient to cover the surface of droplets completely when the amount of PCL is higher, which gives the coalescence of droplets in the process of evaporation of organic solvent and resulting in aggregation of nanocapsules after the removal of organic solvent [32]. This behavior is in agreement with previously published reports for polymeric nanocapsules [33-35]. Polydispersity index values maintains lower than 0.3 for the higher PCL concentration. 


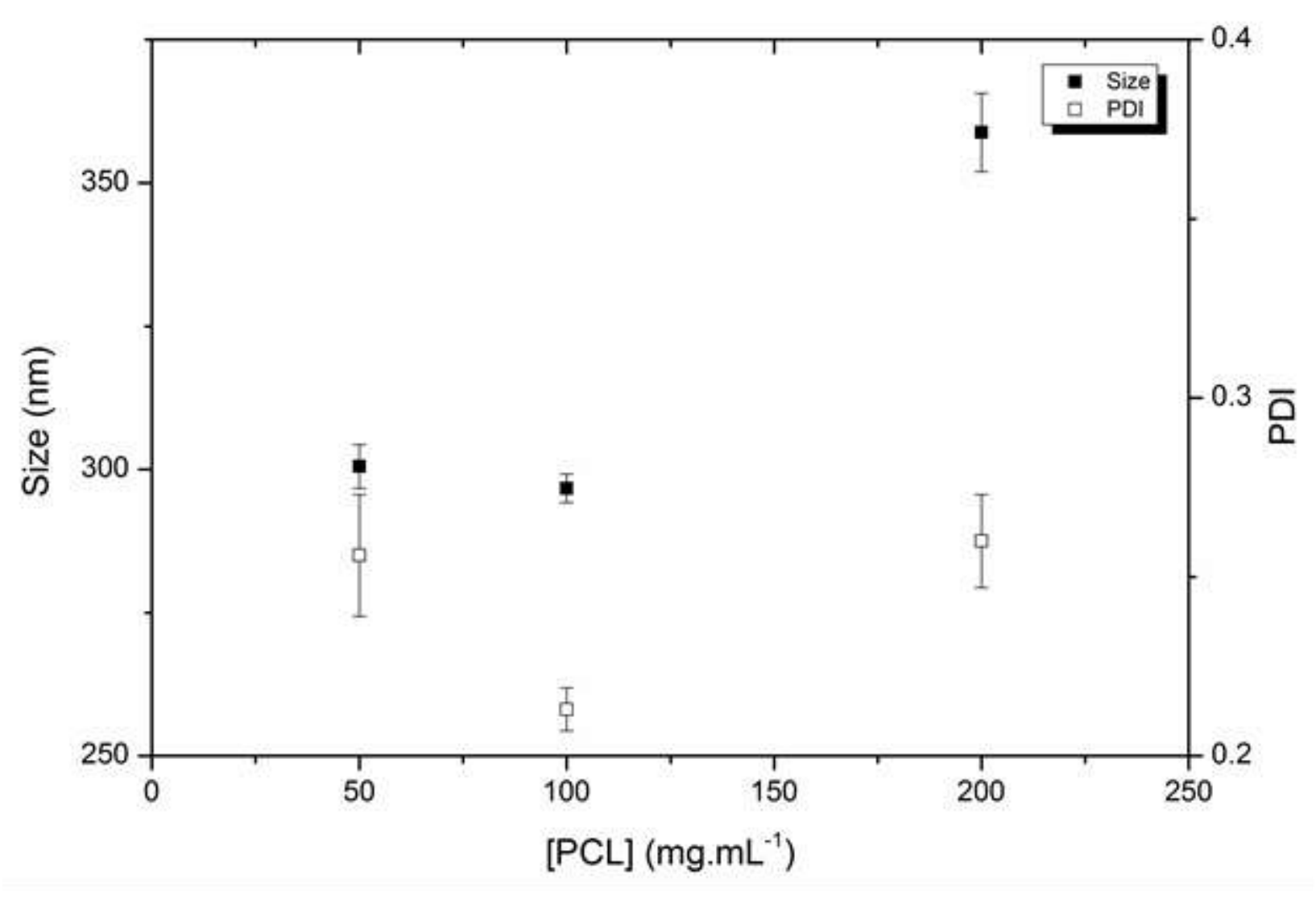

Figure 2: Influence of the PCL concentration on the average hydrodynamic size and PDI of the resulting MagPCL-NC. Data expressed as mean $\pm \mathrm{SD}(\mathrm{n}=3)$. Experimental conditions: initial Mag added: $5 \mathrm{mg}$; PVA concentration: $1 \% \mathrm{w} / \mathrm{v}$, Time of sonication: $3 \mathrm{~min}$.

\subsubsection{Maghemite amount}

The initial ratio of maghemite/PCL was changed in the range 0 to $0.10 \mathrm{mg} \cdot \mathrm{mg}^{-1}$ and the action of this parameter on the diameter and PDI was studied. The initial amount of maghemite used in the formularion of PCL nanocapsules did not act significantly on the physico-chemical properties of the obtained nanocapsules. The obtained average diameters were about $300 \mathrm{~nm}$ with a PDI around from 0.3 (data not showed).

With the results of the optimization study, these experimental parameters were selected for the formulation of PCL nanocapsules: PCL amount (100 mg), Mag amount $(5 \mathrm{mg})$, PVA concentration ( $1 \% \mathrm{w} / \mathrm{v})$ and a time of sonication for the two stages of emulsification process of 3 minutes. With these experimental parameters the obtained MagPCL-NC shows an average diameter of $296 \mathrm{~nm}$, a maghemite content of $7.5 \mu \mathrm{g}$ per mg of nanocapsules and an encapsulation efficiency of $15 \%$ (Erro! Fonte de referência não encontrada.). Figure 3 and 5 show the morphological characterisation of these optimized nanocapsules by SEM and TEM respectively.

Table 1. Physico-chemical properties of PCL nanocapsules. Data reported as mean $\pm \operatorname{SD}(n=3)$. Experimental parameters: PCL amount: $100 \mathrm{mg}$, initial Mag added: $5 \mathrm{mg}$; PVA concentration: $1 \% \mathrm{w} / \mathrm{v}$, Time of sonication: $3 \mathrm{~min}$.

\begin{tabular}{l|l|l|l|l|l}
\hline & SIZE $(\mathrm{nm})$ & PDI & $\begin{array}{l}\text { ZETA POTENTIAL } \\
(\mathrm{mV})\end{array}$ & $\begin{array}{l}\text { MAG LOADING } \\
\left(\mu \mathrm{g} \cdot \mathrm{mg}^{-1}\right)\end{array}$ & $\begin{array}{l}\text { ENCAPSULATION } \\
\text { EFFICIENCY }(\%)\end{array}$ \\
\hline PCL nanocapsules & $346 \pm 1,72$ & $0,190 \pm 0,009$ & $-7,83 \pm 0.07$ & - & - \\
\hline $\begin{array}{l}\text { Mag-PCL nano- } \\
\text { capsules }\end{array}$ & $296 \pm 2,5$ & $0,213 \pm 0,006$ & $-4,39 \pm 0.6$ & 7,5 & 15,2 \\
\hline
\end{tabular}

The maghemite encapsulation efficiency was below 50\%. The obtained results are in line with previous re- 
sults reported by other research groups $[7,20]$ and they would be related with the hydrophilic nature of the surface of maghemite nanoparticles. This fact would be the reason for the moderate retention of these nanoparticles, which would migrate to the outer aqueous phase during the emulsification step of the preparative process of PCL carriers. The high energetic process of agitation used during the emulsification process of the $\mathrm{W} / \mathrm{O}$ emulsion in the aqueous phase of PVA would facilitate the contact between the internal and outer aqueous phase of the multiple emulsion, resulting in maghemite loss.

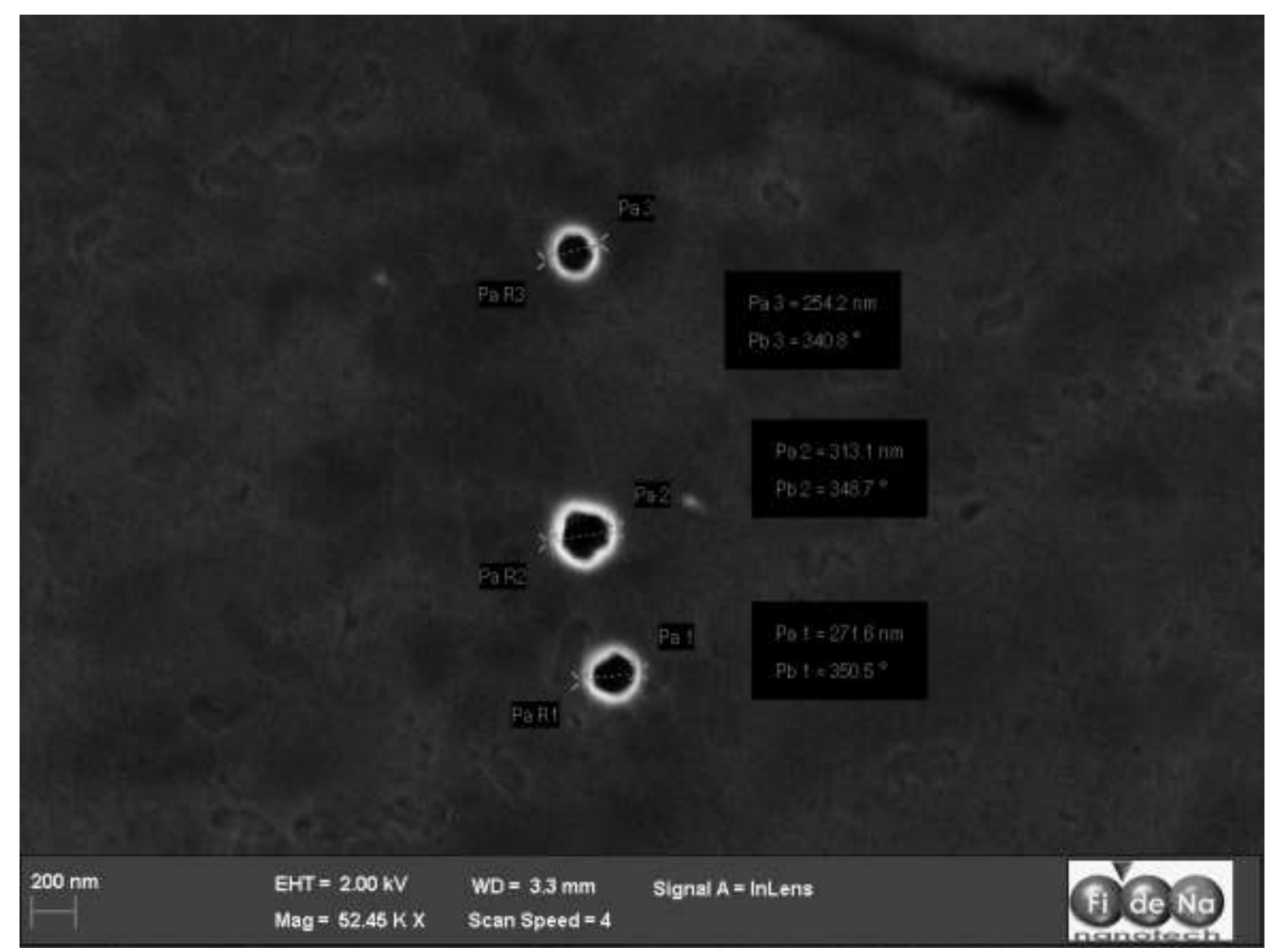

Figure 3: SEM micrograph of Mag-loaded PCL nanocapsules. 


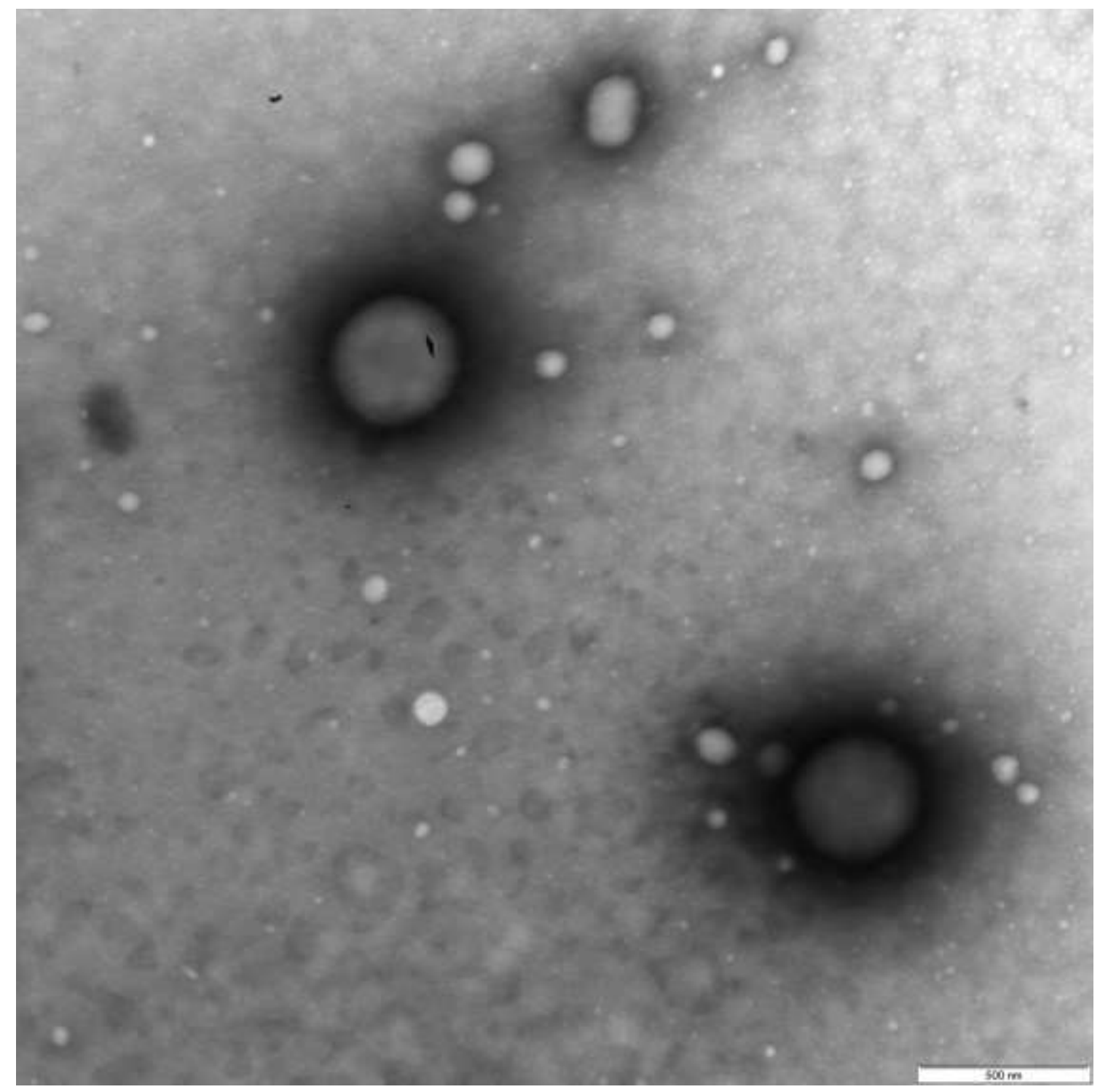

Figure 4: TEM micrographs of Mag-loaded PCL nanocapsules.

Mag-loaded PCL nanocapsules shows spherical morphology with a mean size of nearly $300 \mathrm{~nm}$; similar to that diameter determined by photon correlation spectroscopy.

Figure 6 presents the magnetization as a function of applied magnetic field performed in $20 \mathrm{~K}$ and $300 \mathrm{~K}$ of this sample. Results show that MagPCL-NC exhibited typical superparamagnetic properties with the saturation magnetization of $0.55 \mathrm{emu} / \mathrm{g}$ because the negligible remanence and coercivity in the $\mathrm{M}-\mathrm{H}$ curve at $300 \mathrm{~K}$. On the other hand, in low temperature $(20 \mathrm{~K})$ it can be observed a coercive field at $0.2 \mathrm{kOe}$ and a large remanent magnetization $(0.02 \mathrm{emu} / \mathrm{g})$. These results show that the sample in low temperature presents a blockage state and at room temperature is paramagnetic. These are characteristics of superparamagnetic behavior. This behavior was confirmed from magnetization measurements as a function of temperature performed using $\mathrm{ZFC} / \mathrm{FC}$ protocol with applied magnetic field at $2 \mathrm{kOe}$ applied field in a temperature range between 5 and $300 \mathrm{~K}$ (Figure 6). The maximum value of magnetization was obtained at blocking temperature $\left(\mathrm{T}_{\mathrm{B}}\right)$, at which the magnetic moment were able to rotate. Beyond $\mathrm{T}_{\mathrm{B}}$, the $\mathrm{ZFC}$ magnetization curve nearly overlapped with the FC curve, indicating superparamagnetic behavior. The $T_{\mathrm{B}}$ was determined to be $65 \mathrm{~K}$. Notably, the blocking temperature value corroborated well with the reported literature of superparamagnetic iron oxide nanoparticles [36, 37]. Such superparamagnetic property has been shown critical to the success application of magnetic nanocapsules in areas such as $\mathrm{T}_{2}$-weighted magnetic ressonance imaging, drug delivery and magneto-hyperthermia[38]. 


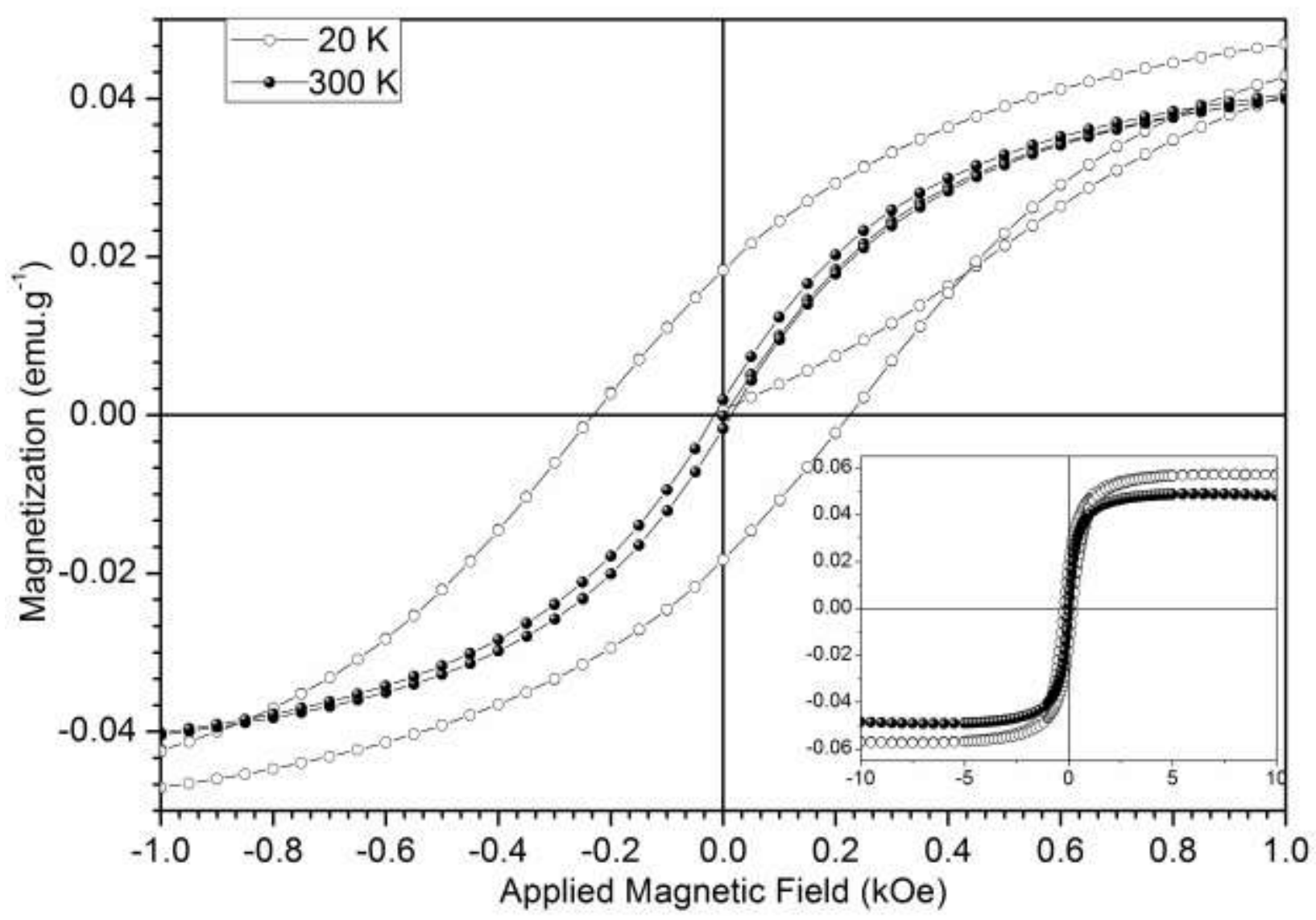

Figure 5: Magnetization as a function of applied magnetic field performed $20 \mathrm{~K}$ and $300 \mathrm{~K}$ of Mag-loaded PCL nanocapsules. At low temperature sample presents a large hysteresis and remanent magnetization. The inset show the saturation magnetization above $5 \mathrm{kOe}$. 


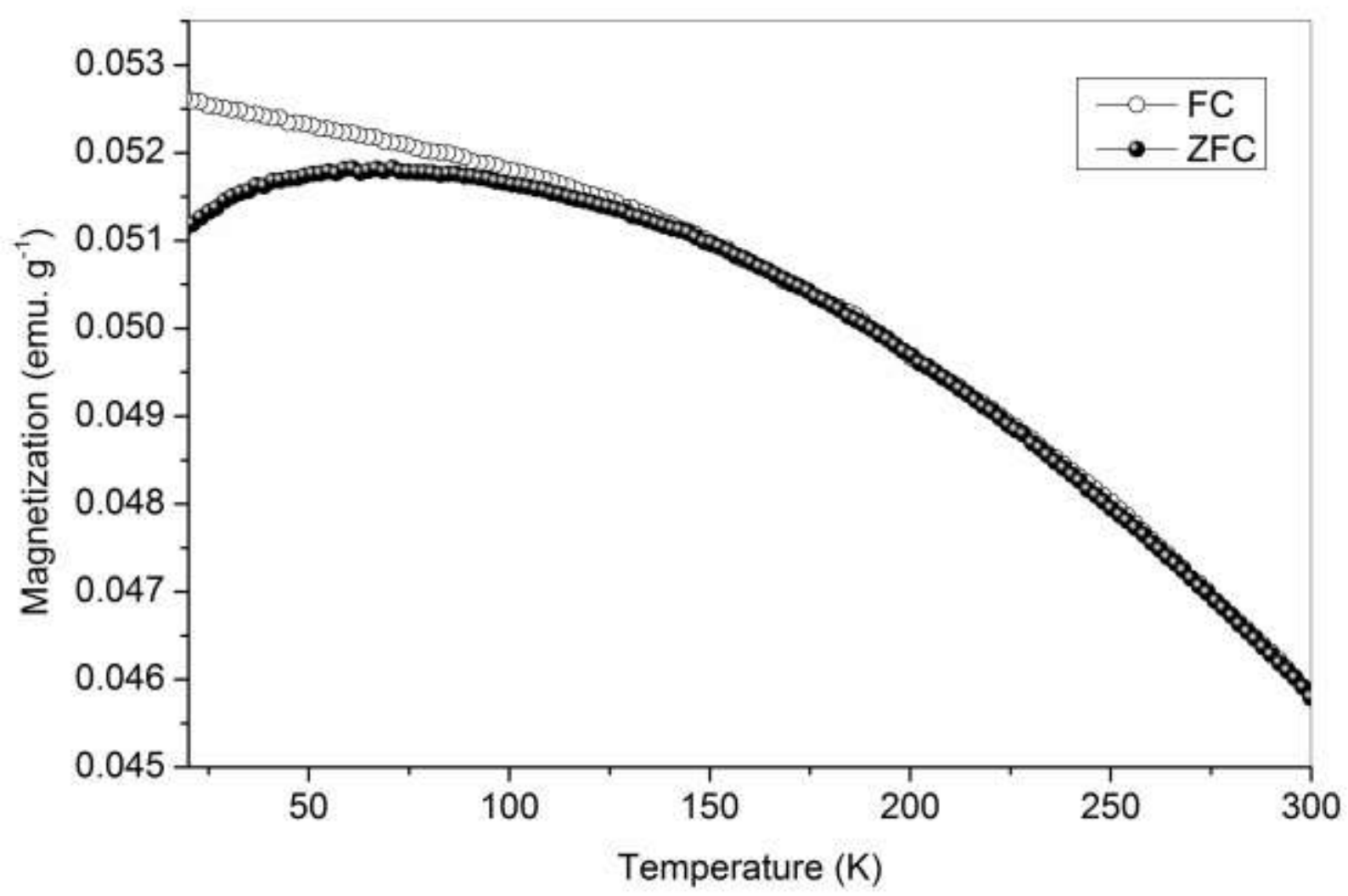

Figure 6: Magnetization as a function of temperature performed with applied magnetic field of 2 kOe in MagPCL-NC . The magnetic irreversibility observed at $65 \mathrm{~K}$ show between of ZFC (shown in black) and field cooled (FC, shown in white) is the blocking temperature associate to superparamagnetic behavior.

For studv the efficiencv of the entranment of maghemite nanonarticles in PCI, nanocansules. we comnared the surface properties of empty PCL nanocapsules with optimized MagPCL-NC and pure maghemite. For this objective, the surface zeta potential of PCL nanocapsules without maghemite (empty), MagPCL nanocapsules and pure maghemite was determined as a function of $\mathrm{pH}$ in the presence of $0.3 \mathrm{mM} \mathrm{KCl}[39]$. Figure 7 summarized these results. The surface zeta potential of the Mag-PCL nanocapsules, in the range of $\mathrm{pH} 3$ to $\mathrm{pH}$ 11, was closest of empty PCL nanocapsules, between 0 and $-5 \mathrm{mV}$. On the other hand, surface zeta potential of maghemite decreased sharply by increasing the $\mathrm{pH}$ conditions (from 0 to $-35 \mathrm{mV}$ ). Considering an iron oxide surface in contact with water, a fully hydroxylated surface should be expected. The net charge of the iron oxide surface is dependent on the protonation/deprotonation of the hydroxyl groups when the $\mathrm{pH}$ of the solution changes [40]. 


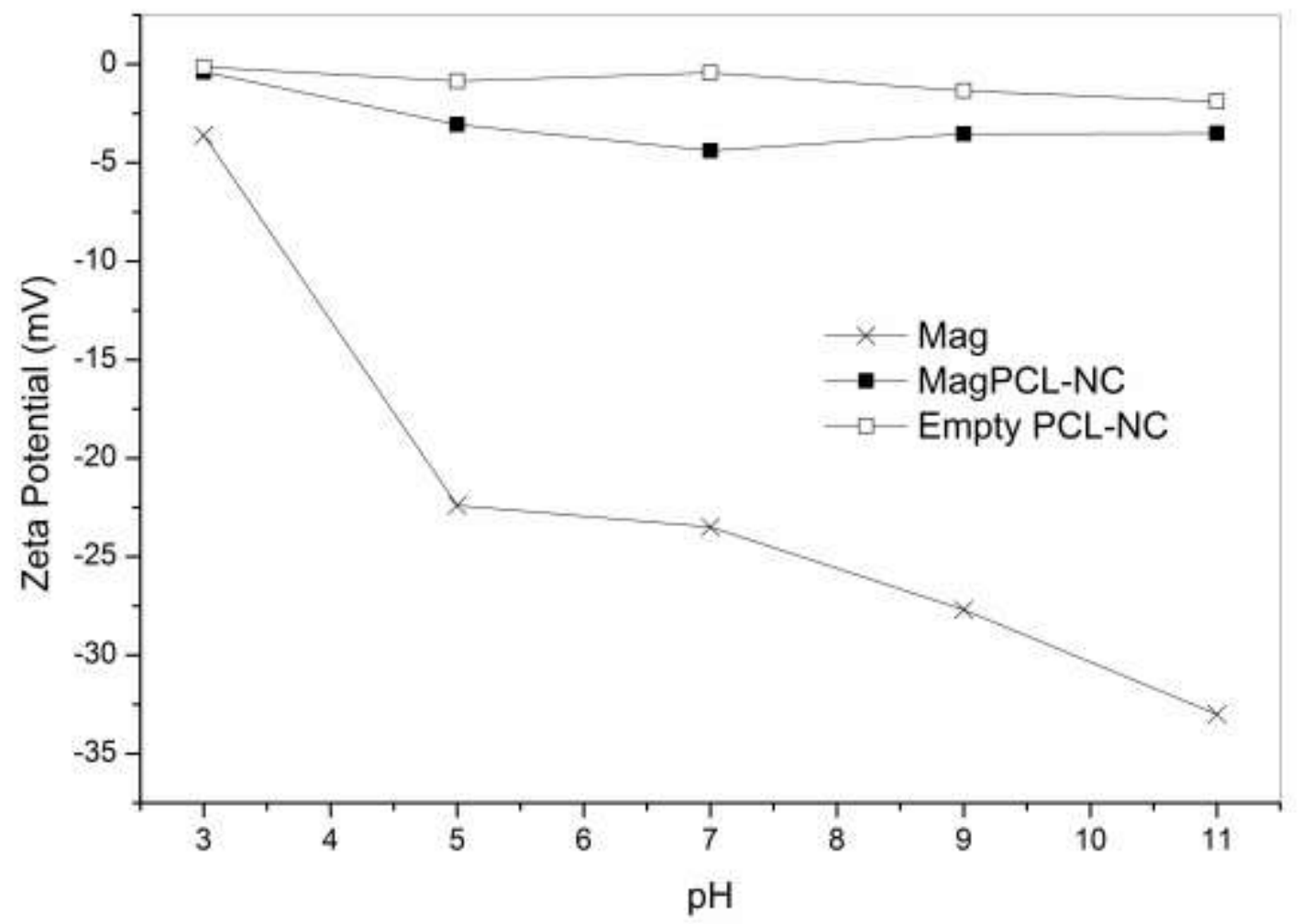

Figure 7: Evolution of the zeta potential of Mag, MagPCL-NC optimized and empty PCL nanocapsules as a function of the $\mathrm{pH}$ medium.

These results indicated that maghemite was totally encapsulated in the resulting PCL nanocapsules. These findings are in agreement with previous determinations described previously $[13,20]$ who have been working with iron oxide-PLGA composite particles. The electrokinetic properties of Mag loaded PCL nanocapsules are in agreement with those of pure PCL, as one would predict in case of an optimum coverage [41].

\section{CONCLUSIONS}

Biodegradable maghemite-loaded PCL systems were prepared by a multiple emulsion-solvent evaporation method with success. Some formulation parameters that influences on nanocapsules diameter, PDI and surface zeta potential were studied. The processing variables could be applied in order to enhance the previously cited properties for PCL nanocapsules. Using the optimized variables, we obtain MagPCL-NC with expected characteristics (mean diameter of $300 \mathrm{~nm}$, PDI about 0.3 and superparamagnetism). We notice that maghemite nanoparticles were encapsulated into PCL nanocapsules with a maghemite content of $7.5 \mu \mathrm{g} / \mathrm{mg}$, in line with those previously reported in the literature, resulting in superparamagnetic behaviour, a critical property to biomedical application devices.

\section{ACKNOWLEDGMENT}

The authors thank the financial support of Capes - DGU 184-09 and MCI Spain - PHB 2008-0044-PC.

\section{REFERENCES}

[1] X. Zhang, W. Jiang, Y. Ye, Z. Feng, Z. Sun, F. Li, L. HaO, J. Chu,"A facile method to synthesize magnetic polymer nanospheres with multifunctional groups", J Magn Magn Mater, v.323, pp.1440-1444, 2011.

[2] M. Kawashita, M. Tanaka, T. Kokubo, Y. Inoue, T. Yao, S. Hamada, T. Shinjo,"Preparation of ferrimagnetic magnetite microspheres for in situ hyperthermic treatment of cancer", Biomaterials, v.26, pp.2231-2238, 2005. 
[3] J.A. Castanharo, I.L. Mello, L.C.D.S. Maria, M.A.S. Costa, M.R. Silva, M.G. OLIVEIRA,"Preparação e caracterização de microesferas poliméricas magnéticas à base de estireno, divinilbenzeno e acetato de vinila", Polímeros, v.22, pp.303-309, 2012.

[4] A. Khan, A.M. El-Toni, M. Alsalhi, A.S. Aldwayyan, M. Alhoshan,"Preparation of magnetic polyacrylonitrile core-shell nanospheres by the miniemulsion polymerization method", Materials Letters, v.76, pp.141-143, 2012.

[5] W. WU, Q. HE, C. JIANG,"Magnetic Iron Oxide Nanoparticles: Synthesis and Surface Functionalization Strategies", Nanoscale Res Lett, v.3, pp.397 - 415, 2008.

[6] J.A.H. Coaquira, C.A. Cardoso, F.Q. SoAres, V.K. Garg, A.C. Oliveira, A.F.R. Rodriguez, D. RABELO, P.C. MORAIS,"Magnetic properties of $\gamma$-Fe2O3 nanoparticles encapsulated in surface-treated polymer spheres", Hyperfine Interact, v.195, pp.149-154, 2010.

[7] L.N. OKassa, H. Marchais, L. Douziech-Eyrolles, S. Cohen-Jonathan, M. SoucÉ, P. Dubois, I. CHOURPA,"Development and characterization of sub-micron poly(d,1-lactide-co-glycolide) particles loaded with magnetite/maghemite nanoparticles", International Journal of Pharmaceutics, v.302, pp.187-196, 2005. [8] C. Sun, O. Veiseh, J. GunN, C. Fang, S. Hansen, D. LeE, R. Sze, R.G. Ellenbogen, J. Olson, M. ZHANG,"In Vivo MRI Detection of Gliomas by Chlorotoxin-Conjugated Superparamagnetic Nanoprobes", Small, v.4, pp.372-379, 2008.

[9] J. QU, G. LIU, Y. WANG, R. HoNG,"Preparation of Fe3O4-chitosan nanoparticles used for hyperthermia", Adv Powder Technol, v.21, pp.461-467, 2010.

[10] M. Mahmoudi, S. SAnT, B. WANG, S. Laurent, T. SEN,"Superparamagnetic iron oxide nanoparticles (SPIONs): Development, surface modification and applications in chemotherapy", Adv Drug Deliver Rev, v.63, pp.24-46, 2011.

[11] S. Blanquer, O. Guillaume, V. Letouzey, L. Lemaire, F. Franconi, C. Paniagua, J. Coudane, X. GARRIC,"New magnetic-resonance-imaging-visible poly( $\varepsilon$-caprolactone)-based polyester for biomedical applications", Acta Biomater, v.8, pp.1339-1347, 2012.

[12] M. HAMOUDEH, H. FESSI,"Preparation, characterization and surface study of poly-epsilon caprolactone magnetic microparticles", J Colloid Interf Sci, v.300, pp.584-590, 2006.

[13] L.N. OKassa, H. Marchais, L. DouZiech-Eyrolles, K. Herve, S. CohEn-Jonathan, E. MunNiER, M. SOUCE, C. LINASSIER, P. DuBOIS, I. CHOURPA,"Optimization of iron oxide nanoparticles encapsulation within poly(D,L-lactide-co-glycolide) sub-micron particles", Eur J Pharm Biopharm, v.67, pp.31-38, 2007.

[14] C.E. Astete, C.S.S.R. Kumar, C.M. Sabliov,"Size control of poly(d,l-lactide-co-glycolide) and poly(d,l-lactide-co-glycolide)-magnetite nanoparticles synthesized by emulsion evaporation technique", Colloids and Surfaces A: Physicochemical and Engineering Aspects, v.299, pp.209-216, 2007.

[15] X. LiU, M.D. Kaminski, H. Chen, M. Torno, L. TAYlor, A.J. Rosengart,"Synthesis and characterization of highly-magnetic biodegradable poly(d,1-lactide-co-glycolide) nanospheres", Journal of Controlled Release, v.119, pp.52-58, 2007.

[16] N.G. IlbÄCK, M. Nyblom, J. CARlfors, B. FAgERlund-AspenströM, S. TAVElin, A.W. GlynN,"Do surface-active lipids in food increase the intestinal permeability to toxic substances and allergenic agents?", Medical Hypotheses, v.63, pp.724-730, 2004.

[17] B. Aspenstrom-Fagerlund, L. Ring, P. Aspenstrom, J. Tallkvist, N.-G. Ilback, A.W. GLYNN,"Oleic acid and docosahexaenoic acid cause an increase in the paracellular absorption of hydrophilic compounds in an experimental model of human absorptive enterocytes", Toxicology, v.237, pp.12-23, 2007.

[18] B. Aspenström-FAGerlund, B. SundströM, J. TAllkVist, N.-G. IlbäCK, A.W. GlYnN,"Fatty acids increase paracellular absorption of aluminium across Caco-2 cell monolayers", Chemico-Biological Interactions, v.181, pp.272-278, 2009.

[19] B. Aspenström-FAgerlund, J. TAllkVist, N.-G. IlbÄCK, A.W. GlynN,"Oleic acid decreases BCRP mediated efflux of mitoxantrone in Caco-2 cell monolayers", Food and Chemical Toxicology, 2012.

[20] M.F. Silva, A.A. Winkler Hechenleitner, D.M.F. DE OliveirA, M. Agüeros, R. PeÑalva, J.M. IRACHE, E.A.G. PINEDA,"Optimization of maghemite-loaded PLGA nanospheres for biomedical applications", European Journal of Pharmaceutical Sciences, v.49, pp.343-351, 2013.

[21] S. Prior, C. GAMAZO, J.M. IRACHE, H.P. MERKLE, B. GANDE,"Gentamicin encapsulation in PLA/PLGA microspheres in view of treating Brucella infections", International Journal of Pharmaceutics, v.196, pp.115-125, 2000.

[22] M. Furlan, J. Kluge, M. Mazzotti, M. Lattuada,"Preparation of biocompatible magnetite-PLGA composite nanoparticles using supercritical fluid extraction of emulsions", The Journal of Supercritical Fluids, v.54, pp.348-356, 2010.

[23] A. Musyanovych, J. Schmitz-Wienke, V. MaIlander, P. Walther, K. LANDFester,"Preparation of 
biodegradable polymer nanoparticles by miniemulsion technique and their cell interactions(2008), pp. 127139", Macromol Biosci, v.8, pp.127-139, 2008.

[24] J. Kluge, F. Fusaro, N. Casas, G. Muhrer, M. Mazzotti,"Production of PlGA micro- and nanocomposites by supercritical fluid extraction ofemulsions. I. Encapsulation of lysozyme", Journal of Supercritical Fluids, v.50, pp.327-335, 2009.

[25] R. Grillo, N.Z.P.D. Santos, C.R. Maruyama, A.H. Rosa, R.D. Lima, L.F. Fraceto,"Poly( $\varepsilon-$ caprolactone)nanocapsules as carrier systems for herbicides: Physico-chemical characterization and genotoxicity evaluation", J Hazard Mater, v. 231-232, pp.1-9, 2012.

[26] C.E. Mora-Huertas, H. FeSsi, A. ElAisSARI,"Polymer-based nanocapsules for drug delivery", International Journal of Pharmaceutics, v.385, pp.113-142, 2010.

[27] M. Antonietti, K. LANDFESTER,"Polyreactions in miniemulsions", Progress in Polymer Science, v.27, pp.689-757, 2002.

[28] M. Naghibzadeh, A. Amani, M. Amini, E. Esmaeilzadeh, N. Mottaghi-Dastjerdi, M.A. FARAMARZI,"An Insight into the Interactions between $\alpha$-Tocopherol and Chitosan in Ultrasound-Prepared Nanoparticles", J Nanomater, pp.ID 818717, 2010.

[29] A. MukerJeE, J.K. VishwanAthat,"Formulation, Characterization and Evaluation of Curcumin-loaded PLGA Nanospheres for Cancer Therapy", Anticancer Research, v.29, pp.3867-3876, 2009.

[30] A. TRIPATHI, R. GUPTA, S.A. SARAF,"PLGA Nanoparticles of Anti Tubercular Drug: Drug Loading and Release Studies of a Water in soluble drug", International Journal of PharmTech Research, v.2, pp.21162123, 2010.

[31] S. Galindo-RodrigueZ, E. Allemann, H. Fessi, E. DOElKER,"Physicochemical parameters associated with nanoparticle formation in the salting-out, emulsification-diffusion and nanoprecipitation methods", Pharm Res-Dordr, v.21, pp.1428-1439, 2004.

[32] X. Song, Y. Zhao, S. Hou, F. Xu, R. ZhaO, J. He, Z. Cai, Y. Li, Q. Chen,"Dual agents loaded PLGA nanoparticles: Systematic study of particle size and drug entrapment efficiency", Eur J Pharm Biopharm, v.69, pp.445-453, 2008.

[33] T. FECZKó, J. TóTH, G. DósA, J. GYENIS,"Influence of process conditions on the mean size of PLGA nanoparticles", Chemical Engineering and Processing: Process Intensification, v.50, pp.846-853, 2011.

[34] R.M. MAINARDES, R.C. EvANGELISTA,"PLGA nanoparticles containing praziquantel: effect of formulation variables on size distribution", International Journal of Pharmaceutics, v.290, pp.137-144, 2005. [35] H.V. Ven, M. Vermeersch, A. Matheeussen, J. Vandervoort, W. Weyenberg, S. Apers, P. Cos, L. MAES, A. LUDWIG,"PLGA nanoparticles loaded with the antileishmanial saponin $\beta$-aescin: Factor influence study and in vitro efficacy evaluation", International Journal of Pharmaceutics, v.420, pp.122-132, 2011.

[36] T. HYEON, S.S. LEE, J. PARK, Y. CHUNG, H. BIN NA,"Synthesis of highly crystalline and monodisperse maghemite nanocrystallites without a size-selection process", J Am Chem Soc, v.123, pp.12798-12801, 2001. [37] R.K. DUTTA, S. SAHU,"Development of oxaliplatin encapsulated in magnetic nanocarriers of pectin as a potential targeted drug delivery for cancer therapy", Results in Pharma Sciences, v.2, pp.38-45, 2012.

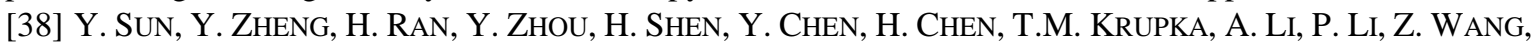
Z. WANG,"Superparamagnetic PLGA-iron oxide microcapsules for dual-modality US/MR imaging and high intensity focused US breast cancer ablation", Biomaterials, v.33, pp.5854-5864, 2012.

[39] J.L. Arias, V. Gallardo, S.A. Gomez-Lopera, R.C. PlazA, A.V. Delgado,"Synthesis and characterization of poly(ethyl-2-cyanoacrylate) nanoparticles with a magnetic core", Journal of Controlled Release, v.77, pp.309-321, 2001.

[40] U. SCHWERTMANN, R.M. CORNELL, Iron oxides in the laboratory: preparation and characterization, Wiley-VCH, Weinheim, 2000.

[41] S.A. Gómez-Lopera, R.C. Plaza, A.V. Delgado,"Synthesis and Characterization of Spherical Magnetite/Biodegradable Polymer Composite Particles", J Colloid Interf Sci, v.240, pp.40-47, 2001. 